\title{
Partha Kar: Covid-19 and ethnicity-why are all our angels white?
}

\author{
Partha Kar consultant in diabetes and endocrinology \\ Portsmouth Hospitals NHS Trust
}

The higher covid-19 mortality rate among people from black and minority ethnic (BME) backgrounds-both in healthcare workers and the general population-has shone a spotlight on an important matter. For those unfamiliar with the issue it may be a shock to realise that people from BME backgrounds, as a whole, have poorer outcomes than other groups.

There's a well established link between mortality rates and socioeconomic deprivation, and there's been enough of a hint that people from BME backgrounds sometimes experience carer apathy too, whether it's down to language barriers or downright racism.

The NHS's general response has been to produce lots of platitudes, a few glossy documents, and lots of verbal commitments to improve. Anyone looking for a previous example need look no further than the system's response to the higher maternal mortality rates in patients from BME

backgrounds. There's been lots of talk and commitment around this, and yet, here we are. ${ }^{12}$

An inherent belief persists that the NHS is fair and equal to all. Or perhaps it's a refusal to acknowledge that we have similar health inequalities to the US. Or maybe an unwillingness to acknowledge an underlying racism in the NHS—one often ignored or cutely termed "unconscious bias," which can be fixed with some "reverse mentoring" or a conference or two.

Regarding the difference in mortality, what about the response from healthcare professionals? It's fascinating to see the science being theorised. Some have asked whether vitamin D might be part of the reason, without any background explanation as to why countries in Africa and south Asia aren't seeing the high mortality rates experienced by people from BME backgrounds in the US and Europe. It could be true-we just don't know.

And so, to covid-19 and the starkly high proportion of BME deaths. Do we discuss, or consider in hushed tones behind closed doors, that BME staff may not be getting the same level of care and attention as other colleagues? Do we say that they don't like following rules and didn't wear their personal protective equipment? Is it because the BME population have adapted more of a "hero" approach and ploughed on? Or because a lot of retired colleagues from BME backgrounds came back to work, when the system should have been aware of the age criteria - and many BME retirees were in the dangerous over 70 bracket?

In a system and society where BME healthcare staff are known to face greater abuse, more discrimination, and lower pay, the higher mortality rate from covid-19 is a culmination of all of these factors. And the solution won't be simple.

Kneejerk responses such as "Let's protect all BME staff" will be impractical to implement, unless age and background comorbidity are also considered. Such responses will increase resentment among colleagues asked to cover for them too. Always remember that, beneath the surface image of staff working in perfect harmony irrespective of skin colour, there exists a wider NHS of deeper divisions.

Part of me hopes that this sad loss of life will focus attention on socioeconomic disparities, the link with racism, and recognition of BME staff. Yet another part of me worries that this story will simply become a footnote as we move on from the covid-19 nightmare.

Muhammad Ali once said, "Why are all the angels white?" To paraphrase that, the current question is what message it sends when we struggle to find one BME individual to represent the NHS in the government's daily briefings. What chance do we have of tackling inequality when our leadership doesn't represent us all?

Competing interests: www.bmj.com/about-bmj/freelance-contributors.

Provenance and peer review: Commissioned; not externally peer reviewed.

1 MBRRACE-UK. Maternal, newborn and infant clinical outcome review programme: saving lives, improving mothers' care. Nov 2018.https://www.npeu.ox.ac.uk/downloads/files/ mbrrace-uk/reports/MBRRACE-UK\%20Maternal\%20Report\%202018\%20-\%20Web\% 20Version.pdf.

2 MBRRACE-UK. Saving lives, improving mothers' care 2019: lay summary. 2019. https:/ /www.npeu.ox.ac.uk/downloads/files/mbrrace-uk/reports/MBRRACE-UK\%20Maternal\% 20Report\%202019\%20-\%20Lay\%20Summary\%20v1.0.pdf.

Published by the BMJ Publishing Group Limited. For permission to use (where not already granted under a licence) please go to http://group.bmj.com/group/rights-licensing/ permissions 
